Hydraulic Engineering Repository

Ein Service der Bundesanstalt für Wasserbau

Beguin, R.; Faure, Y.-H.; Guidoux, C.; Philippe, P. Hydraulic Erosion along the Interface of Different Soil Layers

Verfügbar unter / Available at:

https://hdl.handle.net/20.500.11970/100294

Vorgeschlagene Zitierweise / Suggested citation:

Beguin, R.; Faure, Y.-H.; Guidoux, C.; Philippe, P. (2010): Hydraulic Erosion along the Interface of Different Soil Layers. In: Burns, Susan E.; Bhatia, Shobha K.; Avila, Catherine M. C.; Hunt, Beatrice E. (Hg.):

Proceedings 5th International Conference on Scour and Erosion (ICSE-5), November 7-10, 2010, San Francisco, USA. Reston, Va.: American Society of Civil Engineers. S. 387-396. 


\title{
Hydraulic Erosion along the Interface of Different Soil Layers
}

\author{
R. Beguin ${ }^{1}$, Y.-H. Faure ${ }^{1}$, C. Guidoux ${ }^{1,2}$, P. Philippe ${ }^{3}$
}

${ }^{1}$ Laboratoire d'étude des Transferts en Hydrologie et Environnement, University of Grenoble, BP53, 38041 GRENOBLE Cedex 09, France ; email: remi.beguin@ ujfgrenoble.fr

${ }^{2}$ Geophyconsult, Savoie Technolac BP. 73377 LE BOURGET DU LAC Cedex; email : cyril.guidoux@geophyconsult.com

${ }^{3}$ CEMAGREF, Aix-en-Provence, France ; email : pierre.philippe@cemagref.fr

\begin{abstract}
Contact erosion occurs at the interface of two different soil layers when particles of the finer layer are removed by the flow and transported through the pores of the coarser layer. Whenever this kind of internal erosion occurs in embankment dams, dykes or in their foundations, severe consequences are likely. As contact erosion may be seen as a type of surface erosion, river erosion models have been used by previous authors to model this phenomenon, mainly for contact between sand and gravel layers. Thanks to a specific experimental device, these results are extended to finer soils, broadly-graded, made of clays, silts and sands. The available data for contact erosion is sum-up and the adequate laws for different situations are underlined. Then, the concept of erosion threshold, useful to evaluate dykes' safety, is discussed and linked with the erosion variability and evolution with time.
\end{abstract}

\section{INTRODUCTION}

At the interface between two different soil layers submitted to groundwater seepage, contact erosion is likely. Particles of the finer layer may be destabilized by the water flow and transported through the pores of the coarser layer. This requires two conditions. First, the coarse layer has to be geometrically open to the other layer, that is to say, to have pores sufficiently large so that fine particles can pass through them. Previous authors have tried to quantify this condition in terms of ratio of the grading of both soils and call it a filter criterion (Sherard et al., 1984). Second, the flow has to be sufficient to detach the particle but also to transport it. This is the hydraulic condition for erosion. The construction of earth embankment in fluvial valleys is a typical situation in which a coarse alluvial foundation can be in contact with a finer soil which constitutes the core of an earth structure. Nowadays, the filter criterion is normally fulfilled for the construction of new hydraulic structures, but the length of dykes often obliges the use of in-situ material and sometimes this material is not ideal. Moreover, many older dykes have been built without consideration of the filter criterion and no one knows how they will behave.

Therefore, contact erosion may be an important safety risk for dykes. This kind of erosion has been studied in the context of seaside dykes by various authors from the Netherlands (Bezuijen et al., 1987; Den Adel et al., 1994) and by (Brauns, 1985; Wörman et al., 1992). They usually consider the case of sand erosion, in the configuration of a coarse layer above a fine layer that will be called "Configuration 
1 " in this paper. This does not correspond to the majority of river dykes, usually made of a silt or clay core in contact with gravel layers, with the fine layer above the coarse layer, called here "Configuration 2". In this context, the work done by (Schmitz, 2007) provides measured flow velocities initiating erosion of a silt layer above a gravel layer. Nevertheless, the phenomena implicated seem to not be completely understood, and the model proposed by Schmitz only gives a tendency, without explaining all the variability of its data. Extrapolation of these results has to be done with caution.

To evaluate the safety of a dyke where interfaces without geometrical filter criteria are identified, it is fundamental to determine what is the hydraulic loading which will activate the erosion and what is the celerity of the process. Therefore, a suitable experimental device has been set-up to generate contact erosion in the laboratory, in order to identify the key phenomena involved, to quantify the process, and to determine the parameters controlling the erosion. This study focus on the layout of a horizontal interface separating two soil layers which do not verify the geometrical filter criteria. The global water flow is horizontal and tangent to the interface. Sand erosion was considered to compare the results to previous works, but also silt, clay and mixtures closer to soils that can be found in dykes have been used.

\section{Experimental device}

The experimental device is similar to the apparatus used by (Brauns, 1985) and (Schmitz, 2007). A granular interface is submitted to a control flow in order to produce contact erosion (see Figure 1).

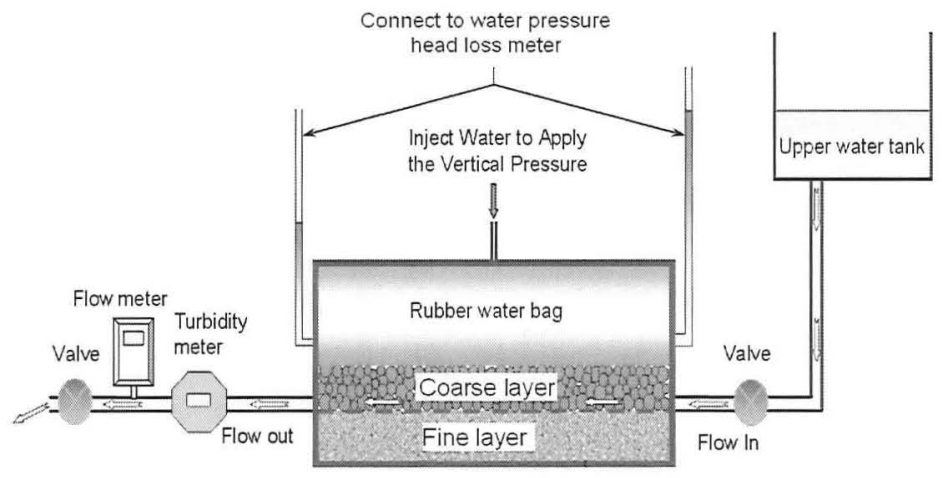

Figure 1. Experimental device set-up for Configuration 1 (the fine layer is above the coarse layer for Configuration 2)

A sample constituted of a fine soil layer and a coarse soil layer is set up in a steel cell of $300 \times 700 \times 265 \mathrm{~mm}$. The fine soil is prepared at the Proctor optimum water content and compacted to reach a density of $90 \%$ of the Proctor maximum density. A rubber bag is put inside the cell, on the sample, and enables to apply a 
controlled static load. A constant hydraulic head is applied at the entry of the cell which is connected to a hydraulic system by two openings $5 \mathrm{~mm}$ height along the width of the cell. The sample is set-up so that the openings of the cell (inlet and outlet) coincide with the coarse layer and so that the flow is tangent to the fine soil surface. As the flow is considered to be influenced by boundary conditions at the entry and the exit, two pieces of geotextile inhibit erosion in these areas. The head loss in the sample is measured by a differential pressure sensor connected to the cell. A flowmeter and a turbidimeter are set up at the exit of the cell. The turbidity measurement is an estimation of the sediment concentration in the effluent, which indicates the amount of fine particles eroded and transported by the flow. Samples of the effluent were regularly taken in order to track the evolution of the grading of the eroded soil. One side of the cell is made from window glass, so that the interface can be observed during erosion process. However, this observation is limited to a small zone close to the window, influenced by side effects.

The fine soils tested are a uniformly graded sand $\left(\mathrm{d}_{50}=250 \mu \mathrm{m}, \mathrm{Cu}=1.7\right)$, a broadly-graded silt $\left(\mathrm{d}_{50}=56 \mu \mathrm{m}, \mathrm{Cu}=6\right)$, Illite $\left(\mathrm{d}_{50}=4 \mu \mathrm{m}, \mathrm{Cu}=5.3\right)$, and gap-graded mixtures of $10 \%$ and $20 \%$ Illite with sand, with $\mathrm{Cu}=\mathrm{d}_{60} / \mathrm{d}_{10}$ and $\mathrm{d}_{\mathrm{x}}$, the $\mathrm{x} \%$-percentile of the soil grain-size. The coarse soils tested are 4 different uniformly graded gravels $(\mathrm{Cu}<2)$ with $\left(\mathrm{D}_{50}=3,5.2,9\right.$ and $\left.17 \mathrm{~mm}\right)$. Each gravel has been tested in combination with each fine soil, with 8 repetitions of the tests with the silt and between 1 and 3 repetitions for the other fine soils.

\section{State of the art and theoretical framework}

During contact erosion, focusing on one pore of the coarse layer just above the top of the fine layer (see Figure 2), we are confronted with a problem of surface erosion of the fine particles by the flow which develops into the pore.

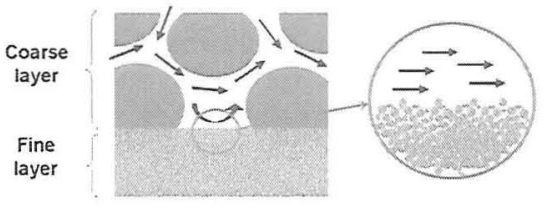

Configuration 1

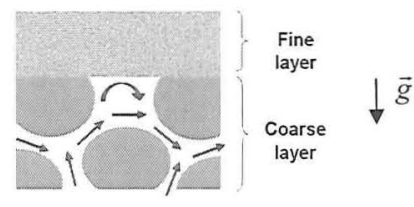

Configuration 2

Figure 2. Contact erosion as a particular surface erosion ( $\vec{g}$ is the gravity)

This phenomenon can be related to classical surface erosion in river context for example, but with many specificities linked to the presence of a coarse layer. The first difference is the characteristics of the flow, which can freely develop in a river but have to follow the numerous changes in section and direction of a pore. Second, a part of the fine layer surface is in direct contact with the coarse layer particles. This area is not directly submitted to the flow but is subjected to the stresses transmitted by the granular skeleton, mainly the weight of the soil column above the interface. Then, the coarse particles are obstacles to the flow, and also obstacle to the transport 
of the fine particles, and a straining mechanism can develop, enhance by electrostatic effects. Finally, contact erosion may appear with the fine layer above the coarse layer (Configuration 2, see Figure 2). Consequently, as the fine soil is eroded from below, the gravity is a destabilizing force for the fine particles and contributes to erosion at the opposite of the classical surface erosion. The methodology used by previous authors to model contact erosion is usually to adapt erosion law elaborated for surface erosion to this particular configuration. For example, to estimate the initiation of erosion, Bezuijen proposed an adaptation of classical (Shields, 1936) criterion in a similar manner than Brauns (Bezuijen et al., 1987). To calculate the shear stress on a particle, he considers that the shear velocity $u^{*}=\tau / \rho$ is linearly function of the pore velocity, $e$ being the coefficient which link these velocities. $\mathrm{He}$ obtains a critical bulk velocity for erosion initiation (equation 1).

$$
u_{c r}=\frac{n}{e} \sqrt{\theta} \sqrt{\left(\frac{\rho_{s}-\rho_{w}}{\rho_{w}}\right) g d_{50}}
$$

With $u_{c r}(\mathrm{~m} / \mathrm{s})$ the erosion initiation bulk velocity, $n$ the porosity of the coarse layer, $e$ an empirical parameter, $\theta$ the Shields parameter, $\rho_{s}(\mathrm{~kg} / \mathrm{m} 3)$ the specific mass of the grains, $\rho_{w}\left(\mathrm{~kg} / \mathrm{m}^{3}\right)$ the specific mass of the fluid, $d_{50}(\mathrm{~m})$ the $50 \%$ percentile of the fine soil size distribution curve and $g\left(\mathrm{~m} / \mathrm{s}^{2}\right)$ gravity. Bezuijen's proposal of using an empirical parameter $e$ illustrates that the main difficulty to adapt surface erosion law to contact erosion is to evaluate the hydrodynamic loading on the particle of the fine soil (Bezuijen et al., 1987). Next, to quantify the erosion and the celerity of the process, Wörman, starting from the Shields criterion, proposed a power law adjustment to model erosion transport (Wörman et al., 1992). With the same objective, Den Adel chose to use statistical distributions to model the hydraulic loading and the particles stability (Den Adel et al., 1994). All these studies have been established and are valid for sand erosion when the coarse layer is above the fine layer. If finer soils are considered as silt or clay, or if the fine soil is above the coarse soil, many differences appear. First, the adhesive forces will play an important role which is not taken into account in the previous models. In this case, it is proposed (Guidoux et al., 2010) to modify Brauns formula in order to extend the validity of this law for silts by adding a term which considers these adhesive contributions (equation 2).

$$
u_{c r}=0.7 n \sqrt{\left(\frac{\rho_{s}-\rho_{w}}{\rho_{w}}\right) g d_{H}\left(1+\frac{\beta}{d_{H}^{2}}\right)}
$$

With $d_{H}(\mathrm{~m})$ the effective diameter proposed by (Kozeny, 1953), which conserves the specific area of the grading, and $\beta\left(\mathrm{m}^{2}\right)$ a coefficient function of the adhesive properties of the particles considered. Moreover finer particles will be transported by suspension in the coarse layer unlike sand which is transported by bedload. Bedload transport implies a shielding effect which limits erosion as the amount of sand 
transported increase. After a given length, the quantity of sand transported will reach equilibrium. For finer particles transported by suspension, this effect is very weak and usually no equilibrium is reached until the exit of erosion zone. In consequence, the transport model proposed by Wörman and Den Adel cannot be applied for silt and clay (Den Adel et al., 1994; Wörman et al., 1992). Transport concentration in the fluid is not enough high to reduce erosion. In this case, existing surface erosion model can be adapted (Bonelli et al., 2006). This model is a threshold law expressed in terms of shear stress applied to the eroded soil of the form:

$$
\begin{aligned}
& \varepsilon=k_{e r}\left(\tau-\tau_{c}\right) \quad \text { si } \quad \tau>\tau_{C} \\
& \varepsilon=0 \quad \text { si } \quad \tau \leq \tau_{C}
\end{aligned}
$$

$k_{e r}(\mathrm{~s} / \mathrm{m})$ is the coefficient of erosion which characterizes the kinetic of the phenomenon, $\tau(\mathrm{Pa})$ is the shear stress applied by the flow on the interface, $\tau_{C}(\mathrm{~Pa})$ is the threshold shear stress of the fine soil and $\varepsilon\left(\mathrm{kg} / \mathrm{s} / \mathrm{m}^{2}\right)$ is the erosion rate per unit time and surface eroded. The shear stress is estimated by measuring the gradient $i$ in the coarse layer, and evaluating its specific area $A_{s}$ thanks to the size distribution curve and empirical formula, or deduced from permeability (equation 4).

$$
\tau=\frac{n \rho_{w} g i}{A_{S}}
$$

This expression correlates well to data obtained with our apparatus (see Figure 3).

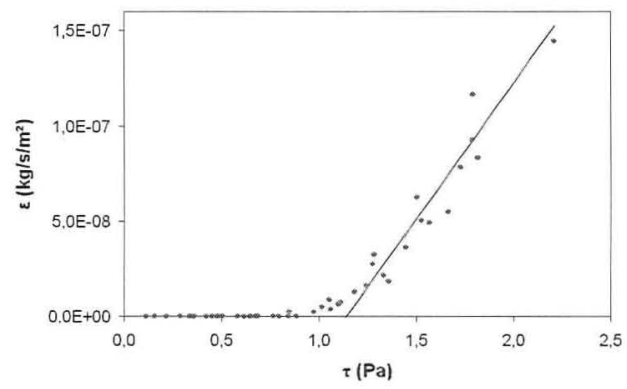

Figure 3. Experimental data for one couple fine soil/coarse soil and application of equation (3)

For the configuration 2, formula based on Shields criterion cannot be used. As the gravity has an opposite contribution, the phenomena involved are different and Schmitz proposed a model with two contributions: the mechanical shear resistance of the soil and the equilibrium of the soil consider as a dense fluid over the water (Schmitz, 2007). If the interface remain well define during the erosion process, erosion law of type (3) could also be used. In both configurations, fine layer above or below the coarse layer, the fine particles need to be transported trough the pores of 
the coarse layer after being detached. If not, the fine particles will accumulate until blocking the coarse layers pores. Transport of fines in a porous medium is a complex phenomenon which has been widely studied for many applications. It implies to take into account the hydrodynamic loading on the particle which will move the particle but also the possible trapping of the particle, geometrically in a small pore, hydraulically in a slow velocity zone, or by adhesion to the coarse grains, especially for clay with electrically charged particles.

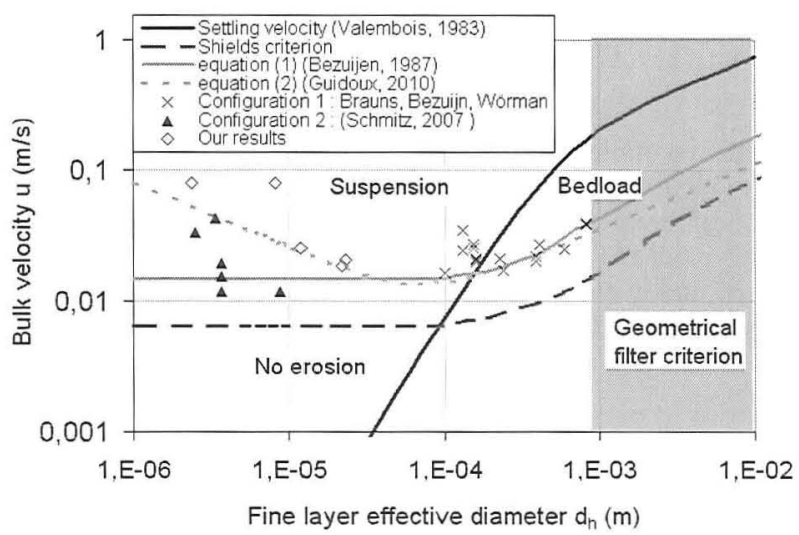

Figure 4. Critical bulk velocity for a coarse layer $\mathbb{D}_{50}$ around $20 \mathrm{~mm}$

As underlined, contact erosion is similar to classical surface erosion but also a complex combination of various phenomena. The knowledge about the initiation of contact erosion was summarized in Figure 4. Results are usually expressed in critical bulk velocity initiating the process, bulk velocity being a parameter easy to measure during experimentation and computable on the field if in-situ permeability is known. The criterion that defines the start of erosion differs from author to author : the first sediment observed visually in the effluent (Brauns, 1985), a chosen quantity transported (Bezuijen et al., 1987), a no null turbidity after 30 minutes for our experiments (Guidoux et al., 2010) and even no threshold (Wörman et al., 1992). As it can be seen, the threshold velocities are not so different and lay between 0.01 and $0.1 \mathrm{~m} / \mathrm{s}$. These results are collected for data with a coarse layer of $D_{50}$ close to 20 $\mathrm{mm}$. If all the experimental data are plotted in function of the $\mathrm{D}_{50}$ regardless of the fine soil, it can be seen that the grading of the coarse layer has a weak influence on the critical velocity (see Figure 5). A tendency could be to a small increase of the critical velocity with increasing $\mathrm{D}_{50}$. In terms of flow regime in the coarse layer, the limit of Darcy regime is always exceeded, and hence in a regime where inertial contribution cannot be neglected. Temporal fluctuations and turbulence seem to not be the criterion for initiation of erosion as sometimes evocated. These results seem to show that for a bulk velocity inferior to $10 \mathrm{~mm} / \mathrm{s}$ no contact erosion is possible. 
Indeed, among all the experiments done, only one critical value inferior to $10 \mathrm{~mm} / \mathrm{s}$ has been measured by Schmitz and this was only in configuration 2 (Schmitz, 2007). This have a great importance for dyke safety as it can provide a first order indication of erosion initiation. Nevertheless, it has been noticed that the notion of threshold depend on each author and two models, from Wörman and Den Adel, consider that there is no threshold but very small erosion rates for low velocity (Den Adel et al., 1994; Wörman et al., 1992). It means that for long duration as it is the case in-situ, eroded mass may be very large. This reveals an important question that has not been greatly considered concerning the evolution of the erosion with time.

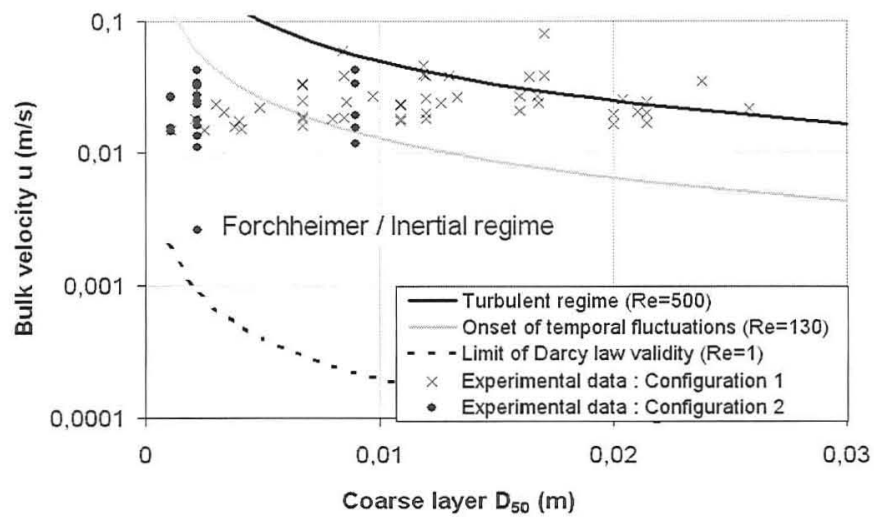

Figure 5. Critical bulk velocity for different fine soil in function of the $D_{50}$ of the coarse layer and limits of flow regime linked with particle Reynolds number: $\operatorname{Re}=u d / v$, with $u(\mathrm{~m} / \mathrm{s})$ bulk velocity, $v\left(\mathrm{~m}^{2} / \mathrm{s}\right)$ viscosity of the fluid

\section{Evolution of erosion with time}

The turbidimeter used in our experiment can follow the evolution in time of erosion with a measurement each second of the concentration in sediment of the effluent. Experiments done with various fine soils show a similar behavior. When increasing the velocity to a chosen value, a peak of turbidity is first observed and then a progressive decrease until reaching a null turbidity for low velocity or a, a priori constant, erosion rate when exceeding the critical velocity (see Figure 6). This means that even below the critical velocity a small amount of soil is eroded at the beginning of the step.

This can be explained using the statistical model proposed by (Den Adel et al., 1994). In the coarse layer, the flow is spatially variable due to the numerous changes in section and direction. This results in a variable hydraulic loading on the surface of the fine soil. Den Adel chose to use a log-normal distribution for the possibilities of destabilization of particles. Velocity measurements have been performed inside a refractive index matching porous medium, made of glass beads 
and mineral oil. Particle Image Velocimetry has been used to obtain velocity fields of the porous flow. Thanks to these results, shear-stresses could be estimated from measured velocity gradients. This study has shown that velocities and shear-stress are distributed following a log-normal law (see Figure 7). This distribution have a large extend along the high values that means that even for a low bulk velocity, local shear-stress can be quite important. This spreading of hydraulic loading exists for classical surface erosion but this effect is largely more pronounced in a porous flow.

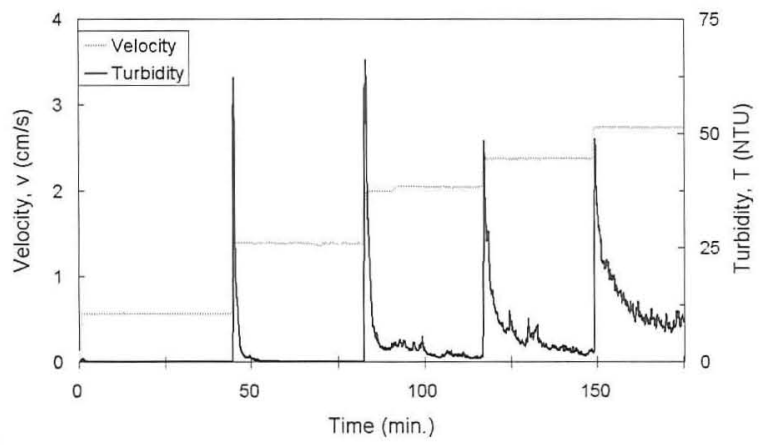

Figure 6. Classical result of contact erosion experiment, velocity and turbidity as a function of time

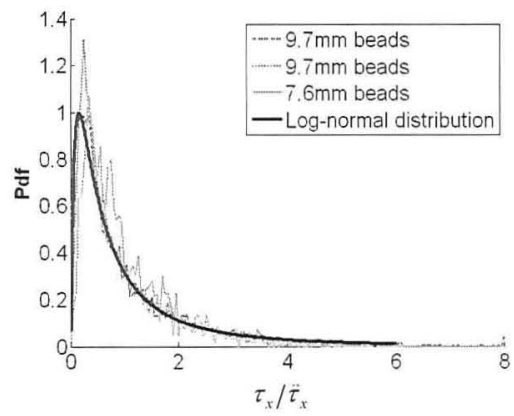

Figure 7. Shear stress distribution calculated from PIV measurement in a refractive index matching porous medium made of glass beads and mineral oil

Following the same argument, the stability of the fine particles can be expressed as a distribution (Grass, 1970). Particles hidden by others or with stronger adhesive links need a higher loading to be destabilized than others. The initial peak can be associated to the erosion of the particles more sensible to erosion. The 
following decrease is linked to a hardening of the eroded surface. The particles which have the stronger resistance are not eroded and stay in place, whereas the weakest are eroded. After a while, the global resistance of the surface increases until all the exposed particles cannot be eroded with the actual hydraulic loading. Soils with a wide size distribution curve are likely to exhibit such behavior. Additionally they may contain particles sufficiently big to be geometrically trapped in the pores of the coarse layer. Only fine soil which does not validate the geometrical filter criterion proposed by Sherard, based on the $d_{85}$ has been considered, but this does not mean that all the particles can pass in the pores (Sherard et al., 1984). During the contact erosion process, if one coarser particle is trapped, it will start to clog the coarse layer. Experiments done with natural silt at a constant velocity during various hours have shown this phenomenon (see Figure 8). Grading measurement of the soil before and after the experiment confirmed this selective erosion of the fines (see Figure 9). This segregation is well known in surface erosion in river, and was noticed by (Wörman, 1996) for contact erosion. Wörman studied this phenomenon for different well-graded sand and proposed an expression of the evolution of the surface clogged with time. The same behavior was observed for experiments in configuration 2 , which are affected inversely by gravity. After several hours, the erosion stops. This implies that even though a global classical geometrical criterion is not fulfilled, if there exists some particles sufficiently big to clog the pores of the coarse layer, erosion will stop after a certain amount of erosion. In terms of design of a hydraulic structure, if this erodible amount is sufficiently small to not modify the performance of the structure, it could be considered to not fulfill the geometrical criteria in this specific situation.
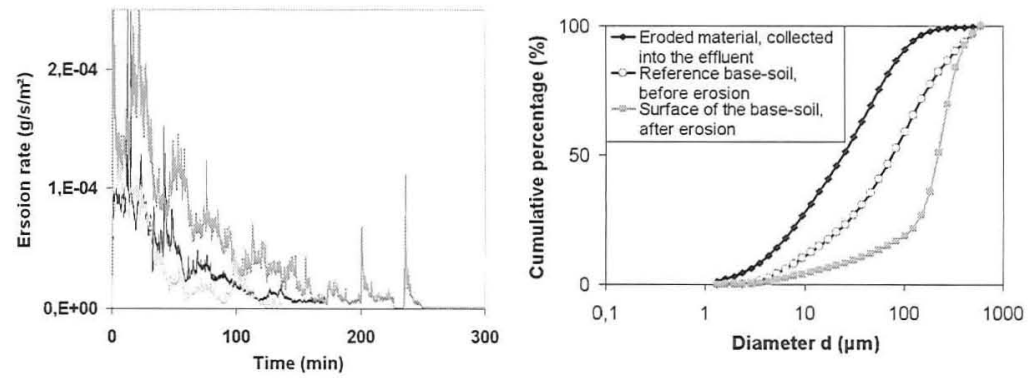

Figure 8. Evolution of erosion rate with Figure 9. Size distribution curves of the time at constant velocity for 3 experiments with a natural silt in Configuration 1 natural silt used, before experiment, in the effluent and on the interface after the end of experiment

\section{CONCLUSION}

Contact erosion is a process similar to surface erosion but with many specifics linked to the presence of the coarse layer. A synthesis of studies undertaken 
on contact erosion has been conducted and coherence was found in the results but their field of validity is limited to sand. For finer soils, an adapted surface erosion model based on hydraulic shear-stress has been proposed and agrees with our data. It has also been noticed that no agreement exists in the literature on the existence of an erosion threshold and it has been shown that this can be attributed to the porous medium variability and the erosion evolution over time. Finally, it is experimentally observed that the erosion rate decrease with time for broadly graded soils due to the progressive clogging of the coarse soil. In consequence, for real structures, the entire size distribution of the soil is important and may eventually allow relaxation of the geometrical classical filter criteria.

\section{REFERENCES}

Bezuijen, A., M. Klein-Breteller, et al. (1987), Design criteria for placed block revetments and granular filters., in Proceedings of the 2 nd international conference on coastal \& port engineering in developing countries, Beijing, China.

Bonelli, S., O. Brivois, et al. (2006), On the modelling of piping erosion, CR Mecanique 334(8-9), 555-559.

Brauns, J. (1985), Erosionsverhalten geschichteten Bodens bei horizontaler Durchstromung, Wasserwirtschaft 75, 448-453.

Den Adel, H., Koenders, M.A. , Bakker, K.J. (1994), The analysis of relaxed criteria for erosion-control filters, Can. Geotech. J. 31(6), 829-840.

Guidoux ,C., Y.-H. Faure, R. Beguin, C.-C., Ho (2010) Contact erosion at the interface between granular filter and various base-soils with tangential flow, J. Geotech. Geoenviron. Eng. Vol. 136, No. 5, may 2010, pp 741-750.

Grass, A.J., 1970, Initial instability of fine bed sand, Proceedings of the American Society of Civil Engineers, Hydraulic Division, Vol.96, No.HY3, pp.619-632.

Kozeny, J. (1953). Hydraulik: Ihre Grundlagen und praktische anwendung. SpringerVerlag, Vienna.

Schmitz (2007). Zur hydraulischen Kontakterosion bei bindigen Basiserdstoffen. $\mathrm{PhD}$ thesis, Universität der Bundeswehr, Munich, Germany.

Sherard, J. L., Dunnigan, L. P., et al. (1984), Basic properties of sand and gravel filters., J. Geotech. Eng-ASCE 110(6), 684-700

Shields, A. (1936), Anwendung der Ähnlichkeitsmechanik und Turbulenzforschung auf die Geschiebebewegung, $\mathrm{PhD}$ thesis, Versuchsanstalt für Wasserbau und Schiffbau, 26, Berlin, Germany

Valembois, J., (1983) Calcul direct de la vitesse de chute d'un grain sphérique dans un fluide, La Houille Blanche, pp. 127-129

Wörman, A., Olafsdottir, R. (1992), Erosion in a granular medium interface, J. Hydraul. Res. 30(5), 639-655

Wörman, A. (1996). "Constitutive equation for filtration of well graded base soil with flow parallel to base/filter interface." Proceedings of GeoFilters 1996, Lafleur, J. and Rollin, A.L., Editors, Montreal, Canada, 295-304, ISBN-2-55300561-x. 